Supplement of

\title{
High-molecular-weight esters in $\alpha$-pinene ozonolysis secondary organic aerosol: structural characterization and mechanistic proposal for their formation from highly oxygenated molecules
}

Ariane Kahnt et al.

Correspondence to: Magda Claeys (magda.claeys@uantwerpen.be)

The copyright of individual parts of the supplement might differ from the CC BY 4.0 License. 


\section{S1. Previous MS data obtained on the MW 358 ester in the negative ion mode}
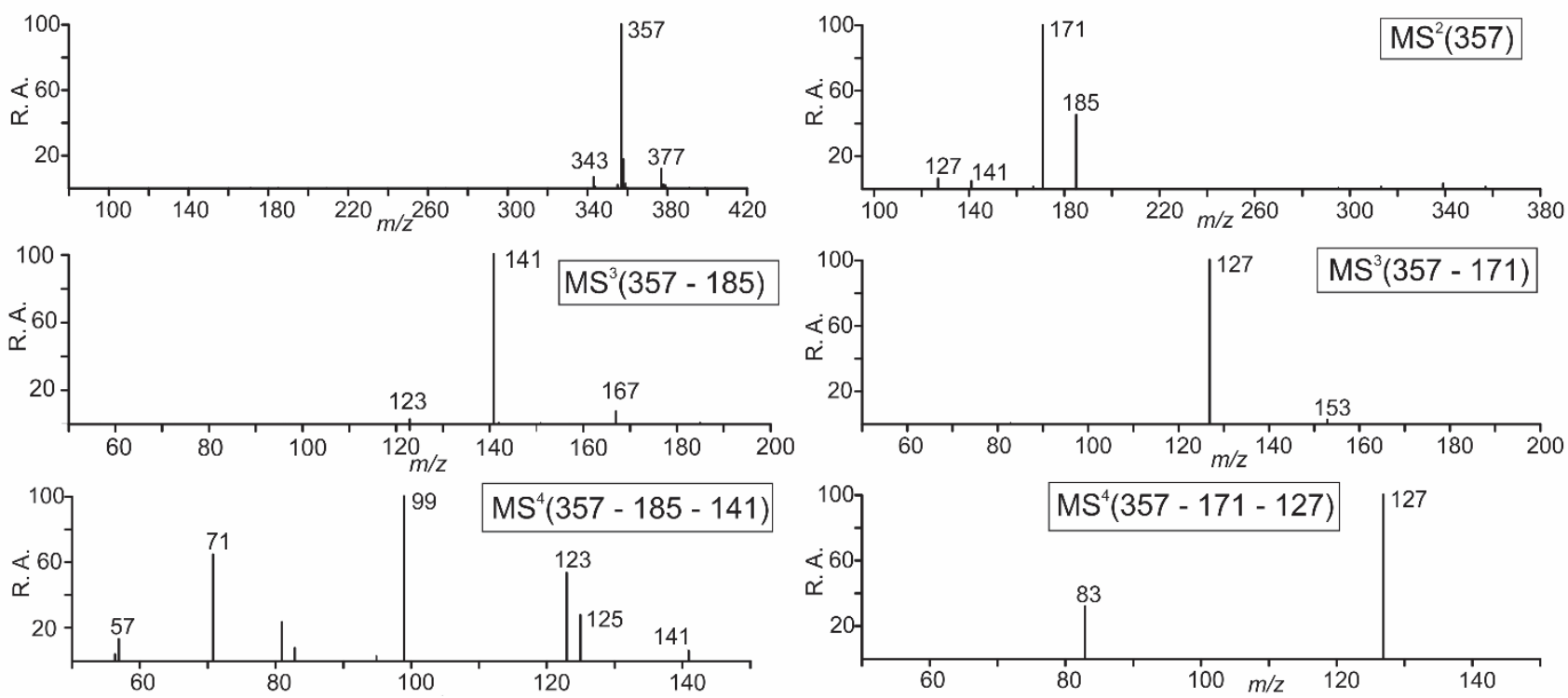

Fig. S1. MS data obtained in the negative ion ESI mode for the MW 358 ester from $\alpha$-pinene/ $\mathrm{O}_{3}$ SOA. The $\mathrm{MS}^{2}$ and $\mathrm{MS}^{3}$ data obtained on $\mathrm{m} / \mathrm{z} 185$ in $\mathrm{MS}^{2}$ support a cis-pinic acid residue, while those on $\mathrm{m} / \mathrm{z} 171$ in $\mathrm{MS}^{2}$ point to a diaterpenylic acid residue. The data are taken from Yasmeen et al. (2010) (Fig. 5).

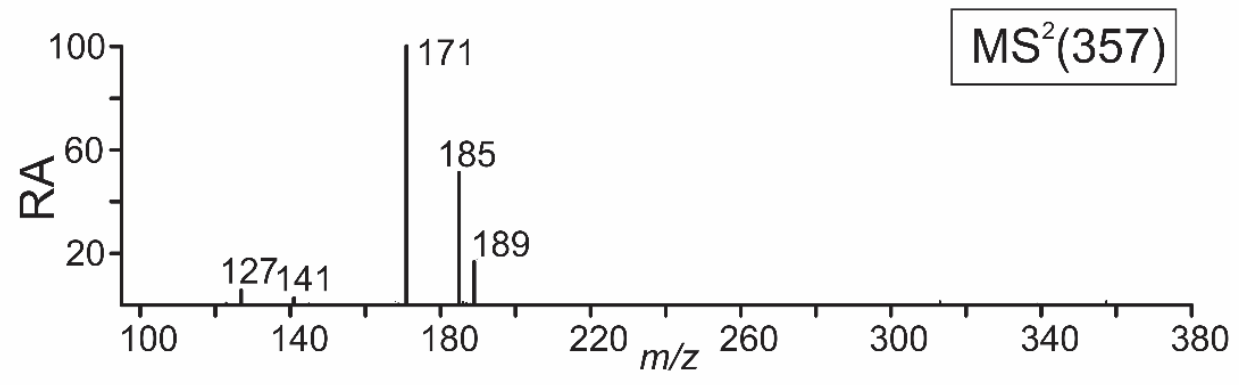

Fig. S2. MS data obtained in the negative ion ESI mode for the minor MW 358 ester from $\beta$-pinene/ $\mathrm{O}_{3}$ SOA. The $\mathrm{MS}^{2}$ and $\mathrm{MS}^{3}$ data (not shown) obtained on $\mathrm{m} / \mathrm{z} 185$ support a cis-pinic acid residue, those on $\mathrm{m} / \mathrm{z} 171$ a diaterpenylic acid residue, and those on $\mathrm{m} / \mathrm{z} 189$ are consistent with diaterpenylic acid (Scheme S2). The data are taken from Yasmeen et al. (2010) (Fig. 6). 
(a)

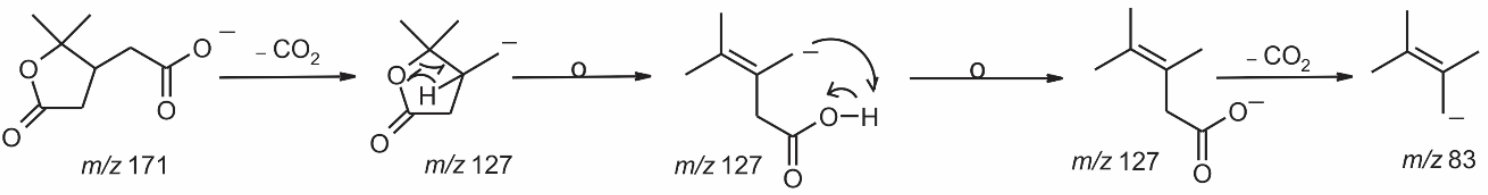

(b)

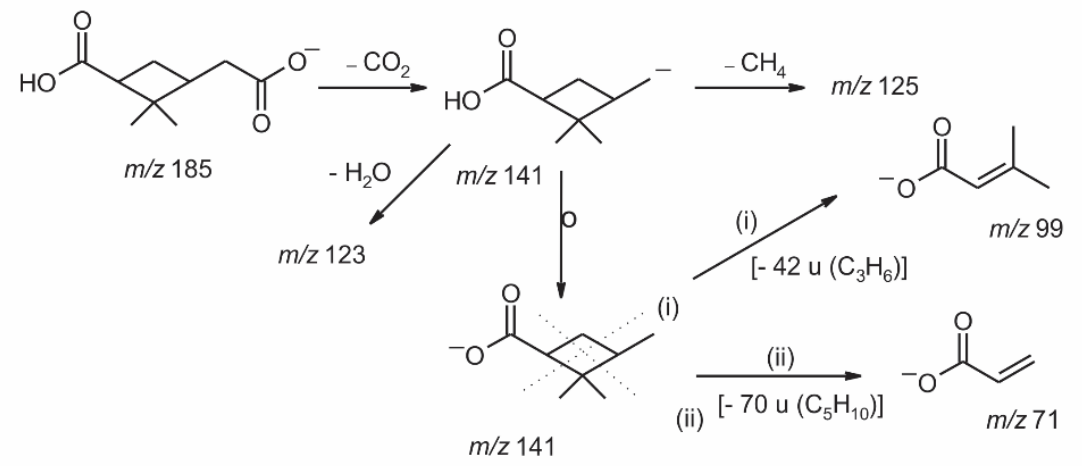

(c)
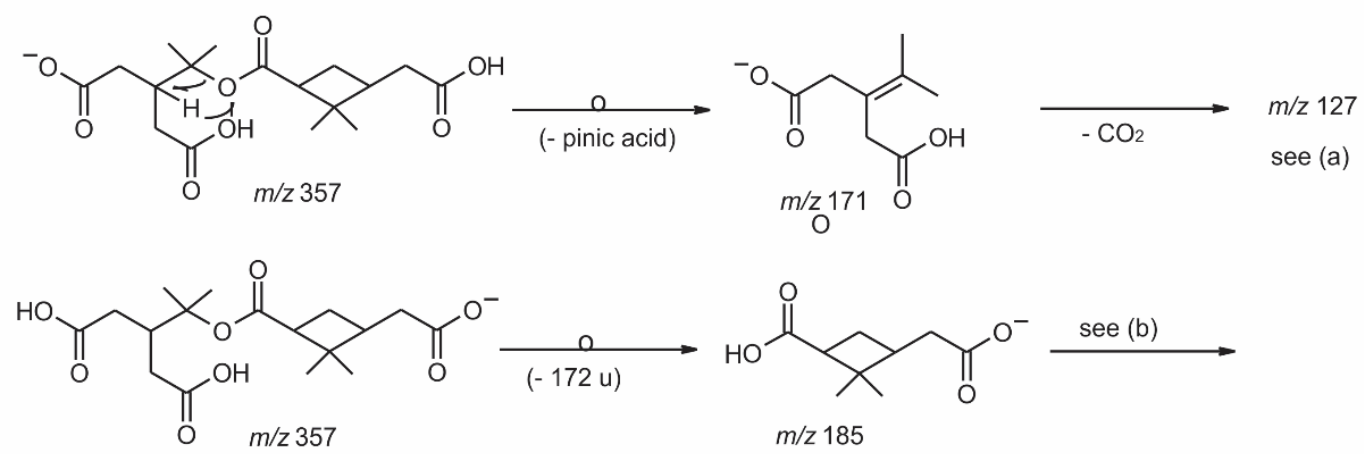

Scheme S1. Proposed fragmentation mechanism for $m / z 171$ (terpenylic acid) (a) and $m / z 185$ (cis-pinic acid) (b) and $m / z 357$ (MW 358 compound from $\alpha$-pinene/ $\mathrm{O}_{3} \mathrm{SOA}$ ) (c). The data are taken from Yasmeen et al. (2010) (Scheme 1).

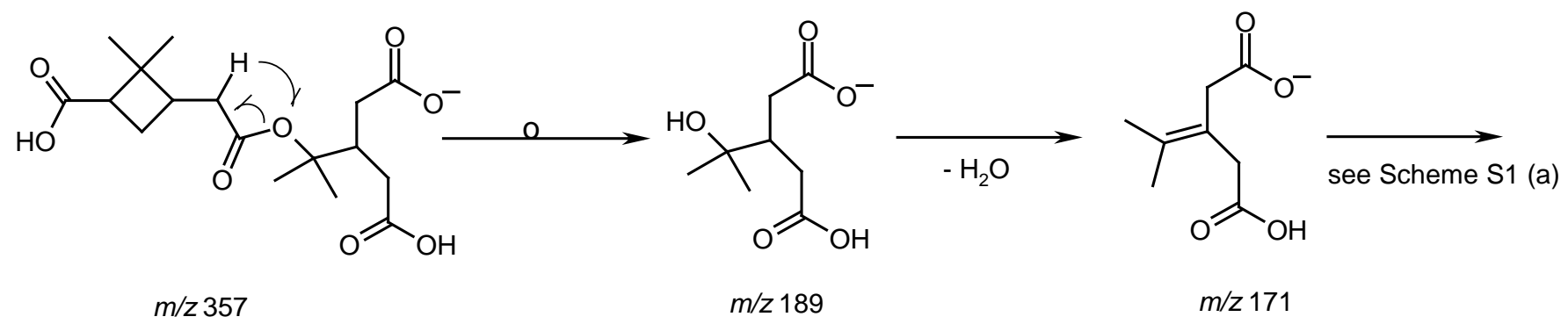

Scheme S2. Proposed fragmentation mechanism for $\mathrm{m} / \mathrm{z} 357$ (minor MW 358 compound from $\beta$-pinene/ $\mathrm{O}_{3} \mathrm{SOA}$ ) resulting in a $\mathrm{m} / \mathrm{z} 189$ product ion (Fig. S2). 


\section{S2. LC data obtained on $\alpha$-pinene/ $\mathrm{O}_{3}$ SOA}
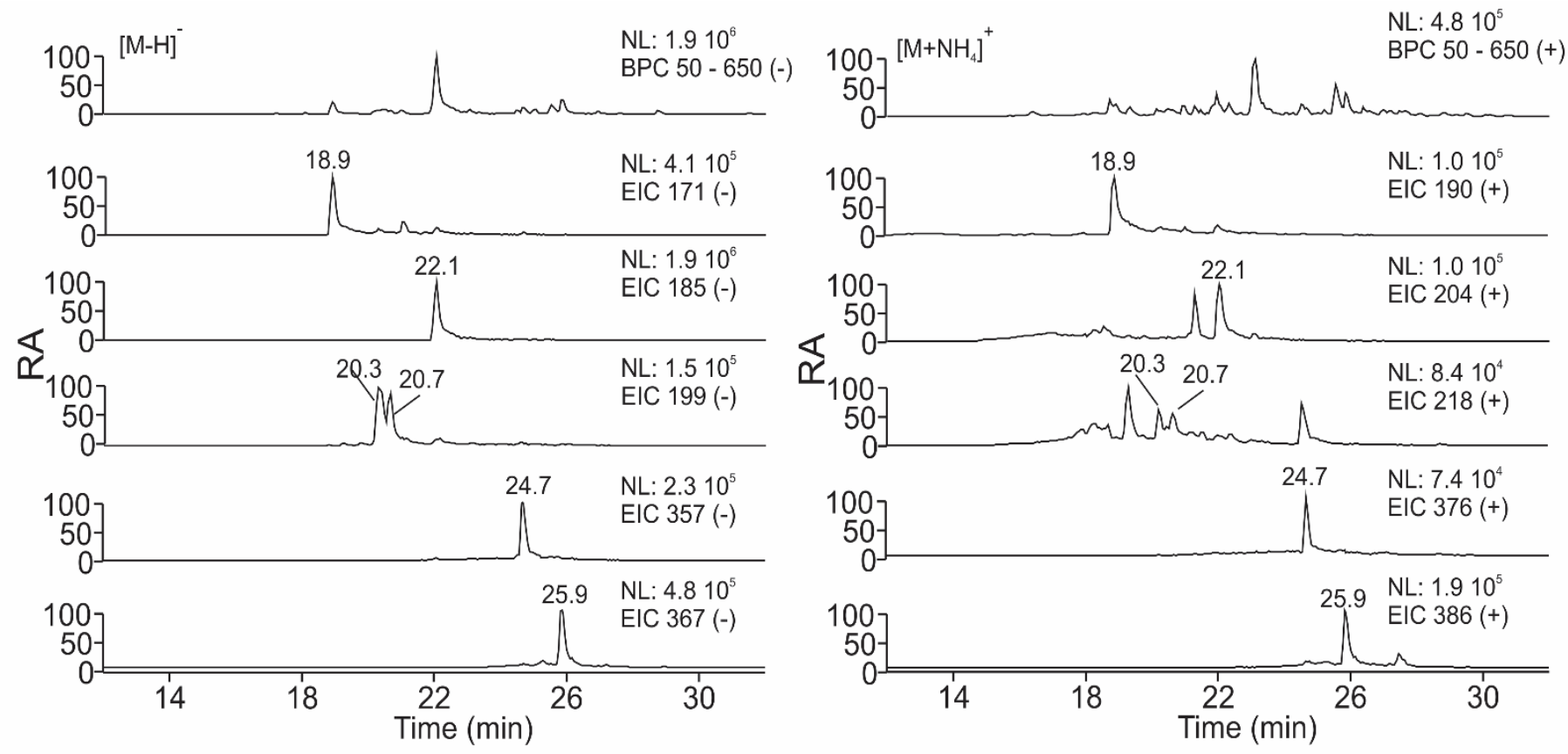

Fig. S3. Base peak chromatograms (BPCs) and extracted ion chromatograms (EICs) of the nonderivatized $\alpha$-pinene/ $\mathrm{O}_{3} \mathrm{SOA}$ sample. EICs are presented for the monomeric and hetero-dimeric species with their isomeric compounds: $m / z 171$ (terpenylic acid), $m / z 185$ (cis-pinic acid), $\mathrm{m} / \mathrm{z}$ 199 (7-hydroxypinonic acid + isomer), m/z 357 (MW 358 ester) and m/z 367 (MW 368 ester ) in the negative ion mode (left panel) and in the positive ion mode (right) as corresponding ammonium adduct ions. Abbreviation: NL, normalization level. 


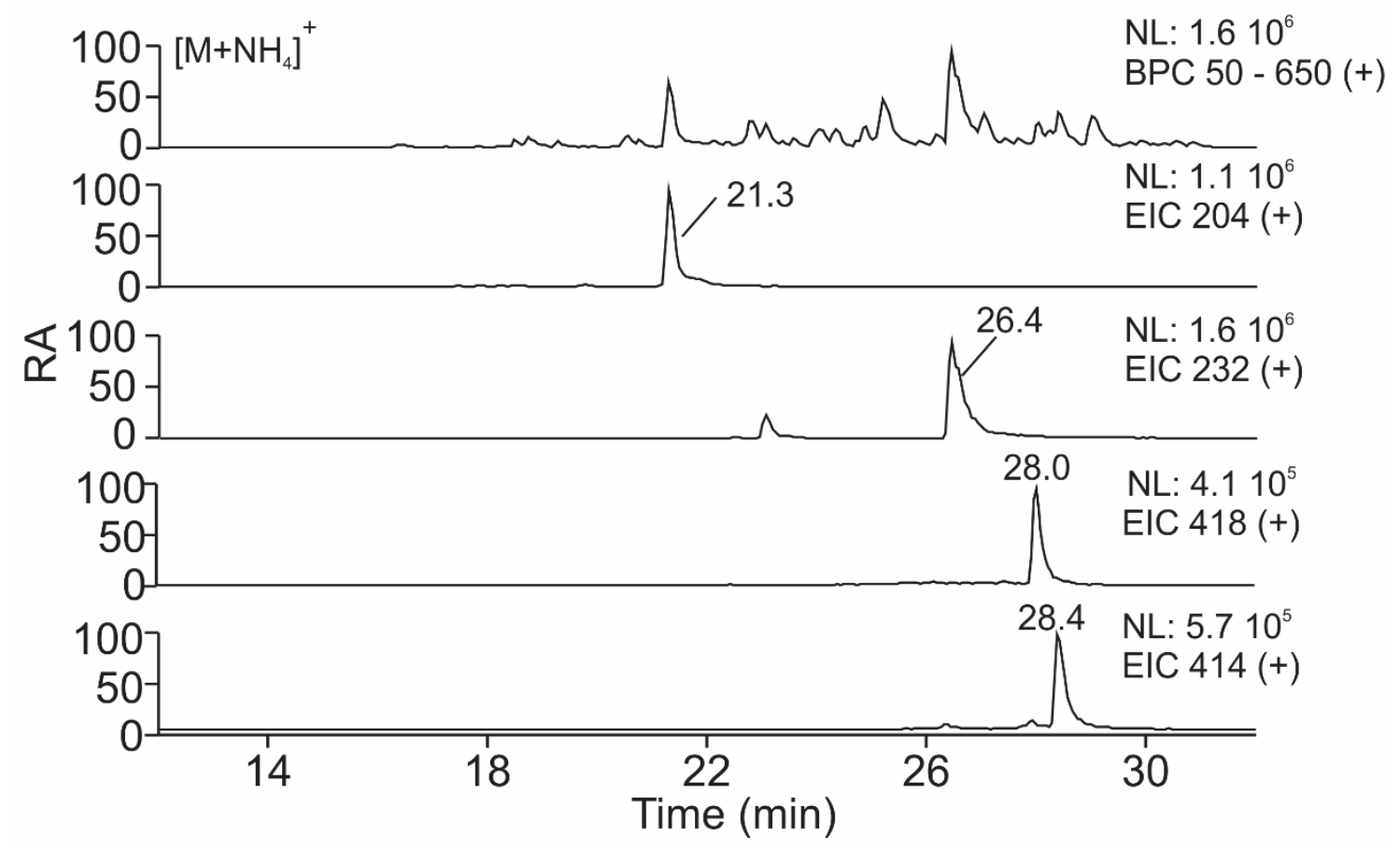

Fig. S4. Base peak chromatograms (BPCs) and extracted ion chromatograms (EICs) of the methylated $\alpha$-pinene $/ \mathrm{O}_{3} \mathrm{SOA}$ sample. EICs are presented for corresponding methylated terpenylic acid ( $m / z$ 190), cis-pinic acid and isomeric compounds (i.e., hydroxypinonic acids) ( $\mathrm{m} / \mathrm{z} 232)$, the trimethylated MW 358 compound ( $\mathrm{m} / \mathrm{z} 418$ ) and the dimethylated MW 368 compound ( $\mathrm{m} / \mathrm{z} 414)$ detected as ammonium adduct ions in the positive ionization mode. Abbreviation: NL, normalization level.

\section{S3. Labeling of cis-pinonic acid}
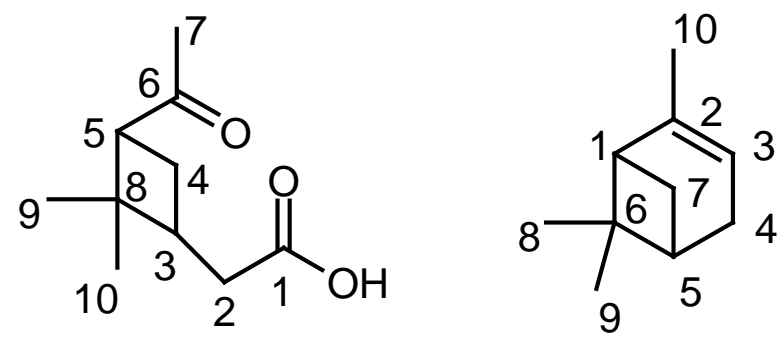

Scheme S3. Labeling of cis-pinonic acid (left). It is noted that another labeling (right) has also been applied in previous studies (Yu et al., 1999; Glasius et al., 2000; Larsen et al., 2001; Winterhalter et al., 2003), based on the $\alpha$-pinene skeleton. In the latter system, 10-hydroxypinonic acid corresponds to 7-hydroxypinonic acid. 
S4. Mechanistic details related to the radicals involved in formation of the MW 368 and 358 esters

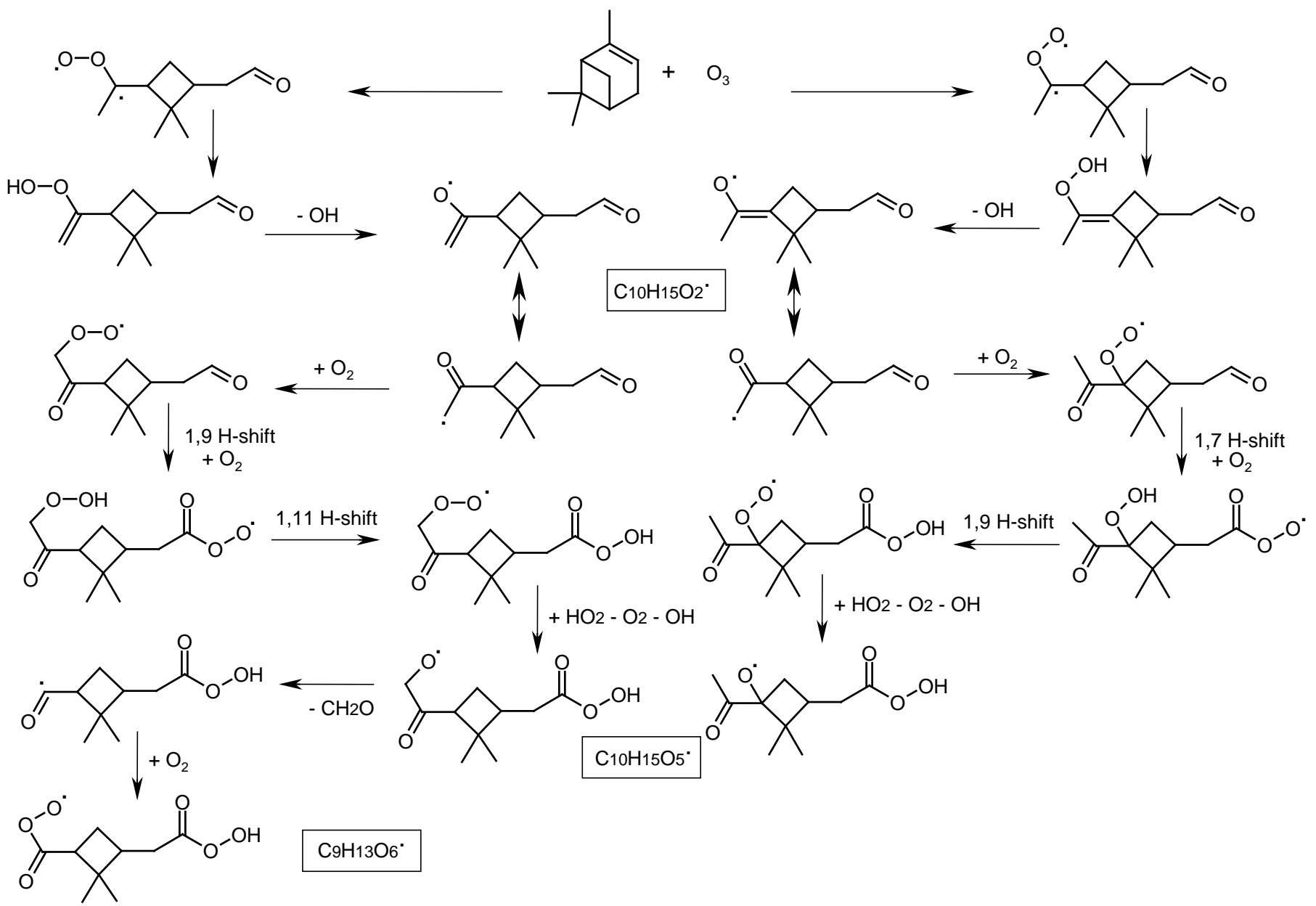

Scheme S4. Proposed mechanism leading to the formation of the alkoxy radicals related to 7- and 5-hydroxypinonic acid (adapted from Zhang et al., 2017) and the acyl peroxy radical related to cis-pinic acid. A $\mathrm{C} 10 \mathrm{H} 15 \mathrm{O} 2$ - radical produced through the vinylhydroperoxide channel serves as the precursor for subsequent autooxidation reactions. H-transfers can take place because of the favorable syn orientation of the substituents on the dimethylcyclobutane ring. 


\section{S5. Mechanistic details related to the formation of the MW 358 ester}

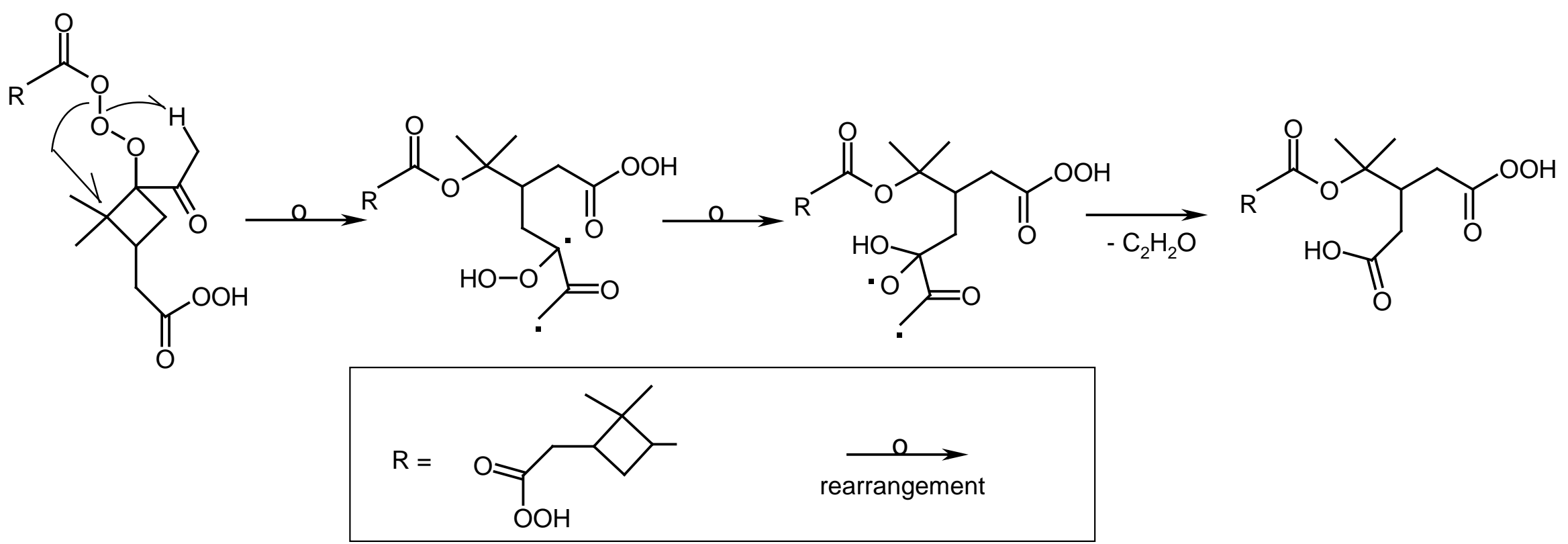

Scheme S5. Proposed rearrangement involved in the loss of ketene from species (d) that is related to the MW 358 ester (Scheme 6). For clarity, the reactions are formulated stepwise, but the loss of ketene is assumed to occur in a concerted manner. 

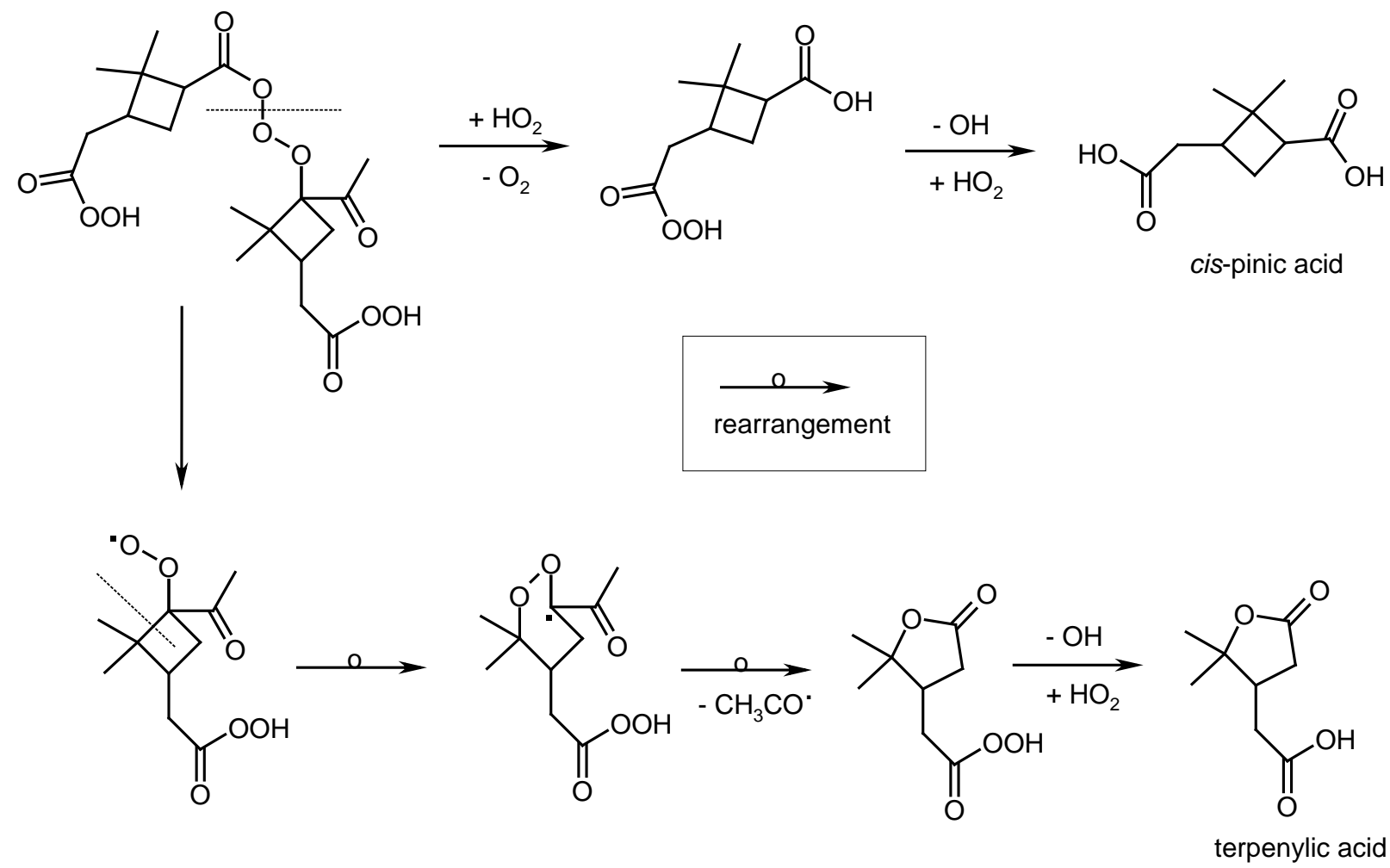

Scheme S6. Proposed mechanism leading to the formation of cis-pinic acid and terpenylic acid through degradation of species (d) related to the MW 358 ester (Scheme 6).

\section{References}

Glasius, M., Lahaniati, M., Calogirou, A., Di Bella, D., Jensen, N. R., Hjorth, J., Kotzias, D., and Larsen, B. R.: Carboxylic acids in secondary aerosols from oxidation of cyclic monoterpenes by ozone, Environ. Sci. Technol., 34, 1001-1010, 2000.

Larsen, B. R., Di Bella, D., Glasius, M., Winterhalter, R., Jensen, N. R., and Hjorth, J.: Gas-phase $\mathrm{OH}$ oxidation of monoterpenes: gaseous and particulate products, J. Atmos. Chem., 38, 231-276, 2001.

Winterhalter, R., Van Dingenen, R., Larsen, B. R., Jensen, N. R., and Hjorth, J.: LC-MS analysis of aerosol particles from the oxidation of $\alpha$-pinene by ozone and $\mathrm{OH}$-radicals, Atmos. Chem.

Phys. Discuss., 3, 1-39, 2003. 
Yasmeen, F., Vermeylen, R., Szmigielski, R., Iinuma, Y., Böge, O., Herrmann, H., W. Maenhaut, W., and Claeys, M.: Terpenylic acid and related compounds: precursors for dimers in secondary organic aerosol from the ozonolysis of $\alpha$ - and $\beta$-pinene, Atmos. Chem. Phys. 10, 9383-9392, doi:10.5194/acp-10-9383-2010, 2010.

Yu, J., Cocker III, D. R., Griffin, R. J., Flagan, R. C., and Seinfeld, J. H.: Gas-phase ozone oxidation of monoterpenes: Gaseous and particulate products, J. Atmos. Chem., 34, 207-258, 1999.

Zhang, X., Lambe, A. T., Upshur, M. A., Brooks, W. A., Gray Bé, A., Thomson, R. J., Geiger, F. M., Surratt, J. D., Zhang, Z., Gold, A., Graf, S., Cubison, M. J., Groessl, M., Jayne, J. T., Worsnop, D. R., and Canagaratna, M. R.: Highly oxygenated multifunctional compounds in a-pinene secondary organic aerosol, Environ. Sci. Technol. 51, 5932-5940, 2017. 